\title{
Estudo das folhas e caule de Hyptidendron canum (Pohl ex Benth.) Harley, Lamiaceae
}

\author{
Tatiana S. Fiuza, ${ }^{1}$ Maria H. Rezende, ${ }^{2}$ Simone M. T. Sabóia-Morais, ${ }^{1}$ \\ Leonice M. F. Tresvenzol, ${ }^{3}$ Heleno D. Ferreira,2 José R. Paula ${ }^{* 3}$
}

\author{
${ }^{1}$ Laboratório de Biologia Celular, Instituto de Ciências Biológicas, Universidade Federal de Goiás, \\ Caixa Postal 131, 74001-970 Goiânia-GO, Brasil \\ ${ }^{2}$ Laboratório de Anatomia Vegetal, Instituto de Ciências Biológicas, Universidade Federal de Goiás, \\ Caixa Postal 131, 74001-970 Goiânia-GO, Brasil \\ ${ }^{3}$ Laboratório de Pesquisa em Produtos Naturais, Faculdade de Farmácia, Universidade Federal de Goiás, \\ Caixa Postal 131, 74001-970 Goiânia-GO, Brasil.
}

\begin{abstract}
RESUMO: Hyptidendron canum (Pohl ex Benth.) Harley, Lamiaceae, é utilizada popularmente como antimalárica, antiinflamatória, antiulcerativa, anti-hepatotóxica e anticancerígena. O objetivo deste trabalho foi realizar o estudo morfo-anatômico das folhas e caules e identificar as principais classes de metabólitos secundários presentes nas folhas de $H$. canum, dados ainda não descritos na literatura. As folhas e caules jovens coletados em Goiânia (GO) foram seccionados à mão livre e preparados para análise microscópica. Foram realizadas reações de identificação de metabólitos secundários do material dessecado e pulverizado. Preparou-se o extrato etanólico bruto, que posteriormente foi fracionado por partição líquido-líquido com hexano, clorofórmio e acetato de etila. As frações foram submetidas à análise cromatográfica em camada delgada (CCD). As lâminas foliares apresentam epiderme adaxial constituída por células poligonais com parede reta. $\mathrm{Na}$ epiderme abaxial observam-se células com parede reta a ondulada e estômatos diacíticos e anisocíticos. Tricomas tectores e glandulares estão presente em ambas as faces da lâmina foliar. O pecíolo apresenta aspecto canaletado, epiderme adaxial e abaxial unisseriada. O caule, em secção transversal possui contorno em geral quadrangular, com presença de tricomas tectores e glandulares. As reações e a CCD das folhas evidenciaram a presença de flavonóides, saponinas, terpenos e lignanas. Este trabalho contribuiu para um maior conhecimento da morfo-anatomia e das classes químicas presentes em $H$. canum.
\end{abstract}

Unitermos: Hyptidendron canum, Lamiaceae, morfo-anatomia, CCD.

\begin{abstract}
Hyptidendron canum (Pohl ex Benth.) Harley, Lamiaceae, is popularly used as an antimalarial, anti-inflammatory, antiulcerative, antihepatotoxic and anticancer agent. The goal of this research was to perform the morphoanatomy study of $H$. canum leaves and stem and identify the main classes of secondary metabolites present in the of $H$. canum leaves. Such data have not been reported in the literature. The young leaves and stems were collected in Goiânia (GO), hand sectioned and prepared for microscope analysis. Reactions were performed for the identification of secondary metabolites of the dried and pulverized material. The crude ethanol extract was prepared and then fractioned by liquid-liquid partition with hexane, chloroform and ethyl acetate. Thin layer chromatography (TLC) analysis was performed on the fractions. The leaf blades presented adaxial epidermis constituted of polygonal cells with straight walls. On the abaxial epidermis cells with straight to wavy walls and diacytic and anisocytic stomates were noted. Non-glandular and glandular trichomes are present on both faces of the leaf blade. The petiole is grooved, and it presents single layered adaxial and abaxial epidermis. The cross section of the stem presents a generally quadrangular contour with the presence of non-glandular and glandular trichomes. The leaf reactions and TLC evidenced the presence of flavonoids, saponins, terpenes and lignanes. This works helps to increase knowledge of the morphoanatomy and the chemical classes present in $H$. canum.
\end{abstract}

Keywords: Hyptidendron canum, Lamiaceae, morphoanatomy, TLC. 


\section{INTRODUÇÃO}

O gênero Hyptidendron pertence à família Lamiaceae que é constituída de ervas, arbustos e árvores, com ramos geralmente quadrangulares. Essa família possui distribuição cosmopolita incluindo cerca de 300 gêneros e 7500 espécies. No Brasil ocorrem 26 gêneros e cerca de 350 espécies (Souza \& Lorenzi, 2005). O gênero Hyptidendron é composto por dezoito espécies exclusivamente lenhosas e freqüentemente arborescentes, compondo duas seções: Hyptidendron e Umbellaria (Harley \& Reynolds, 1992). A maioria das espécies desse gênero abrange o cerrado do planalto brasileiro, incluindo Hyptidendron canum (Pohl ex Benth.) Harley. O bioma cerrado ocupa 20 a 25\% da área total do Brasil, representado por diferentes ecossistemas, dentre eles o cerrado sensu stricto, matas ciliares, cerradão, veredas, campos rupestres (Eitten, 1994).

Essa espécie, inicialmente tratada como Hyptis cana Pohl ex Benth., foi reclassificada por Harley para o gênero Hyptidendron, baseando-se nas características morfológicas e no número de cromossomos $(2 \mathrm{n}=64)$ (Harley, 1988).

H. canum é uma árvore pequena com até $5 \mathrm{~m}$ de altura com os internódios geralmente mais curtos que os pecíolos. As lâminas foliares apresentam predominantemente de 8 a $10 \mathrm{~cm}$ de comprimento e 3 a 7 $\mathrm{cm}$ de largura, com ápice oval, obtuso ou até arredondado, base também arredondada e margens levemente serreadas. Os pecíolos são pequenos, em geral com $1 \mathrm{~cm}$ ou menos de comprimento. As brácteas da inflorescência são reduzidas, com formato oval ou até obovada, esbranquiçadas em ambas as superfícies. As flores se apresentam em cimas dicotômicas, com brácteas lineares ou elípticas de 2 a 3 $\mathrm{mm}$ de comprimento. A corola apresenta cor púrpura, com tubo de 8 a $10 \mathrm{~mm}$ de comprimento, núculas de $4 \mathrm{~mm}$ de comprimento, levemente margeadas (Epling, 1949). As sementes de $H$. canum possuem tegumento castanhoescuro, opaco, rugoso e hilo basal e esbranquiçado. A germinação é fanerocotiledonar e a emergência é epígea (Vuaden et al., 2005).

H. canum é utilizada popularmente pela comunidade do Cerrado Mineiro em forma de chás, infusos e decoctos de folhas e raízes (Brandão, 1991), em função de sua ação farmacológica como antimalárica, antiinflamatória, antiulcerativa, anti-hepatotóxica e anticancerígena (Ferri \& Ferreira, 1992).

$\mathrm{Na}$ revisão bibliográfica realizada não foram encontrados trabalhos sobre a morfo-anatomia das folhas e caules e a determinação dos metabólitos secundários presentes em folhas de $H$. canum. Os estudos botânicos têm como objetivo a identificação inequívoca de uma espécie vegetal, por meio de análise das características anatômicas e morfológicas, procurando destacar aquelas consideradas peculiares de uma determinada espécie e que, em última instância, esteja presente na matéria-prima vegetal.

O estabelecimento de características botânicas comparativas permite detectar a presença de uma ou mais espécies adulterantes (Mentz \& Bordignon, 2004). A anatomia vegetal contribui com informações que podem subsidiar o controle de qualidade de matéria-prima de origem vegetal, de grande valia quando as plantas são comercializadas e/ou utilizadas in nature (Leite et al., 2007).

Objetivou-se neste trabalho o estudo morfoanatômico das folhas e caules e o estudo de metabólitos secundários presentes nas folhas de $H$. canum.

\section{MATERIAL E MÉTODOS}

\section{Material botânico}

As folhas da espécie H. canun (Pohl ex Benth.) Harley foram coletadas no município de Goiânia, Goiás $\left(16^{\circ} 43^{\prime} 26,1^{\prime \prime} \mathrm{S}\right.$ e $49^{\circ} 15^{\prime} 54,8^{\prime}$ ' W, a $885 \mathrm{~m}$ de altitude) no período de fevereiro a abril de 2005. O material botânico foi identificado pelo Prof. Dr. José Realino de Paula, da Universidade Federal de Goiás, e a exsicata encontrase depositada no herbário desta instituição, sob registro UFG/29862. As folhas foram dessecadas em estufa com circulação de ar a $40{ }^{\circ} \mathrm{C}$ e pulverizadas em moinho de facas.

\section{Preparação do material botânico para análise microscópica}

Para a realização do estudo microscópico de $H$. canum foram utilizados fragmentos da nervura principal, região intercostal e bordo apical, mediano e basal da lâmina foliar; e o pecíolo e caule do primeiro e segundo entrenó. As amostras foram fixadas em FPA 70 (formaldeído, ácido propiônico, álcool etílico $70 \%$ ) por $48 \mathrm{~h}$ e posteriormente conservadas em etanol a $70 \%$. Os cortes transversais e paradérmicos foram realizados à mão livre e preparados para análise microscópica usando a coloração azul de Alcian/safranina 9:1 (Bukatsch, 1972 apud Kraus \& Arduin, 1997) e as reações histoquímicas com os reagentes de Steinmetz (Costa, 2001), Sudan III (Sass, 1951), cloreto férrico e lugol (Johansen, 1940). Para as lâminas permanentes utilizou-se a dupla coloração Safrablau (Kraus \& Arduin, 1997). A análise microscópica do pó foi realizada empregando-se o reagente de Steinmetz (Costa, 2001). O registro fotográfico das estruturas anatômicas foi realizado em fotomicroscópio (Zeiss-Axioskop), utilizando filme Kodacolor, ASA 100.

\section{Testes de pureza}

A partir do material botânico pulverizado das folhas de $H$. canum, foram determinados os teores de cinzas totais e insolúveis em ácido e o teor de umidade em triplicata de acordo com a Farmacopéia Brasileira $4^{\mathrm{a}}$ edição (1988). 


\section{Reações de identificação de metabólitos secundários}

A amostra pulverizada das folhas foi submetida às reações para identificação da presença de alcalóides, amido, cumarinas, antraquinonas, esteróides e triterpenos, glicosídeos cardiotônicos, flavônicos, saponínicos e taninos, segundo metodologias adaptadas de Costa (2001). Todos os testes foram feitos em duplicata.

Obtenção do extrato etanólico, frações e determinação do perfil cromatográfico em cromatografia de camada delgada (CCD).

O pó das folhas de $H$. canum foi extraído com etanol a $95 \%$ por maceração, na proporção $1: 1$, à temperatura ambiente por três vezes, por um período de $24 \mathrm{~h}$. O extrato etanólico foi filtrado e concentrado em rotaevaporador à temperatura $\leq 40{ }^{\circ} \mathrm{C}$.

Para obtenção das frações, o extrato etanólico foi dissolvido em metanol, adicionou-se água destilada, até obtenção de uma solução $\mathrm{MeOH} / \mathrm{H}_{2} \mathrm{O}$ 7:3. A solução resultante foi extraída por partições líquido/líquido sucessivas com hexano, clorofórmio ou acetato de etila (Ferri, 1996). As frações hexânica, clorofórmica, acetato de etila e metanol/água obtidas foram concentrados em rotaevaporador em temperatura $\leq 40{ }^{\circ} \mathrm{C}$.

Para realizar a $\mathrm{CCD}$, as frações hexânica, clorofórmica, acetato de etila e metanol/água foram redissolvidas em etanol PA e aplicadas em cromatofolha contendo silicagel $60 \quad \mathrm{~F}_{254}$ (Merck). As análises cromatográficas foram realizadas tendo como fase móvel os eluentes: acetato de etila/ácido fórmico/água (90:5:5) recomendado para análise de taninos condensados pela Farmacopéia Brasileira IV (2003); acetona/tolueno/ácido fórmico (3:3:1) para análise de taninos condensados e hidrolisáveis, flavonóides, terpenos e saponinas; acetato de etila/ácido fórmico/ácido acético glacial/ água (100:11:11:27) para análise de flavonóides; acetato de etila/metanol/água (100:13,5:10) para análise de antraquinonas; e clorofórmio/ácido acético glacial/ metanol/água (64:32:12:8) para análise de saponinas. Para a revelação dos cromatogramas empregou-se $\mathrm{FeCl}_{3} /$ $\mathrm{HCl}$ para detecção de flavonóides, taninos condensados e hidrolisáveis; vanilina $/ \mathrm{H}_{2} \mathrm{SO}_{4}$ para terpenos, flavonóides, saponinas, taninos condensados e hidrolisáveis; $\mathrm{KOH}$ a $10 \%$ para antraquinonas, antronas , antrol e cumarinas; NP 1\% (ácido difenilbórico 1\% em metanol)/ PEG (polietilenoglicol) 4000 a 5\% em etanol para flavonóides, aloína; anisaldeído ácido sulfúrico para lignanas. Após aplicação dos reveladores, as cromatoplacas foram observadas em luz visível a UV $365 \mathrm{~nm}$ e analisadas de acordo com Wagner \& Bladt (2001).

\section{Doseamento de flavonóides}

O doseamento de flavonóides totais foi realizado, em triplicata, de acordo com a metodologia descrita na Farmacopéia Brasileira IV (2001) para calêndula.

\section{RESULTADOS}

\section{Descrição microscópica das folhas e caule}

As folhas de $H$. canum são hipoestomáticas. A epiderme adaxial, em vista frontal, apresenta células com parede anticlinal reta espessada (Figura 1A) e a epiderme abaxial apresenta células com parede reta à ondulada, estômatos anisocíticos (Figura 1B) e diacíticos (Figura $1 C)$.
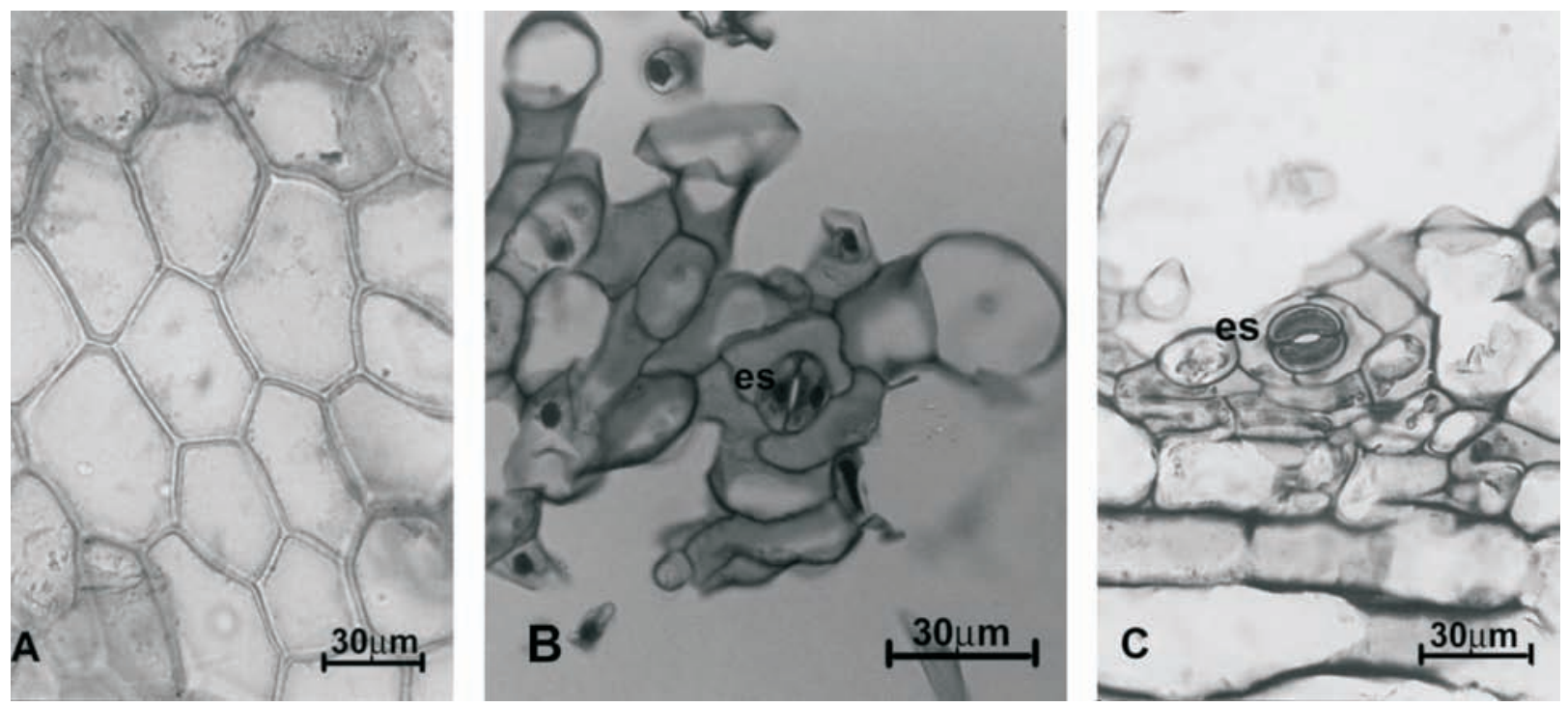

Figura 1. Secções paradérmicas da lâmina foliar de Hyptidendron canum. A. epiderme adaxial: aspecto geral das células epidérmicas em vista frontal; coloração com azul de alcian/safranina. B. epiderme abaxial: detalhe de estômato anisocítico; coloração Safrablau. C. epiderme abaxial: detalhe de estômato diacítico; coloração Safrablau. es: estômato. 
Em secção transversal da lâmina foliar, observase na epiderme adaxial, raros tricomas glandulares do tipo capitato com pedúnculo curto unicelular e cabeça unicelular, tricoma glandular peltado com cabeça tetracelular, tricomas tectores simples com uma ou mais células (Figura 2A) e tricomas tectores ramificados pluricelulares (Figura 2B). A epiderme adaxial é uniestratificada seguida de hipoderme bisseriada (Figura 3A). O mesofilo é dorsiventral com parênquima paliçádico unisseriado e parênquima lacunoso plurisseriado com células braciformes (Figuras 3A e 3B). Observam-se cristais em forma de drusas em células do parênquima lacunoso (Figura 3C). Os feixes vasculares de menor calibre localizam-se próximos à epiderme abaxial e apresentam extensão de bainha esclerenquimática em direção à hipoderme (Figura 3B). A epiderme abaxial é densamente pilosa apresentando vários tricomas tectores pluricelulares simples e ramificados (Figuras 2C, 2D e 3C), tricomas glandulares capitados apresentando pedúnculo curto unicelular com cabeça unicelular (Figura 2E) e bicelular, tricomas glandulares com pedúnculo bicelular com cabeça unicelular (Figura 2F) e tricomas glandulares peltados com cabeça tetracelular (Figuras $2 \mathrm{G}$ e $2 \mathrm{H}$ - vista frontal). O bordo nas regiões basal, mediana e apical da lâmina foliar apresenta a mesma organização estrutural. A epiderme é unisseriada revestida por cutícula delgada em ambas as faces, hipoderme uni a bisseriada na face adaxial. Entre a epiderme e o último feixe vascular ocorre parênquima paliçádico e lacunoso (Figuras 4A e 4B).

A nervura principal, em secção transversal, apresenta face adaxial acuminada e abaxial convexa (Figura 5A), epiderme adaxial (Figuras 5A e 5B) e abaxial (Figuras 5A e 5C) unisseriada, apresentando tricomas tectores ramificados e tricomas glandulares capitados com pedúnculo curto unicelular e cabeça globosa bicelular (Figura 5B). Presença de colênquima angular com até quatro camadas de células abaixo da epiderme em ambas as faces, parênquima cortical com células de tamanhos variados (Figuras 5A, 5C e 5D) e endoderme contendo grãos de amido (Figura 5E). O sistema vascular é colateral em forma de arco fechado (Figuras 5A e 5D).

A secção transversal da região mediana do pecíolo apresenta contorno côncavo na face adaxial e convexo na face abaxial (Figuras 6A e 6B), epiderme unisseriada com tricomas tectores ramificados (Figura 6D) e tricomas glandulares tanto na face adaxial quanto abaxial, presença de colênquima angular com até quatro camadas de células em toda a sua extensão (Figuras 6A, 6B e 6C). O parênquima cortical possui células isodiamétricas de tamanhos variados podendo conter grãos de amido. $\mathrm{O}$ sistema vascular em forma de ferradura é constituído por feixes colaterais, evidenciando calota esclerenquimática externamente ao floema (Figuras 6A, 6B, 6C, 6E e 6F).

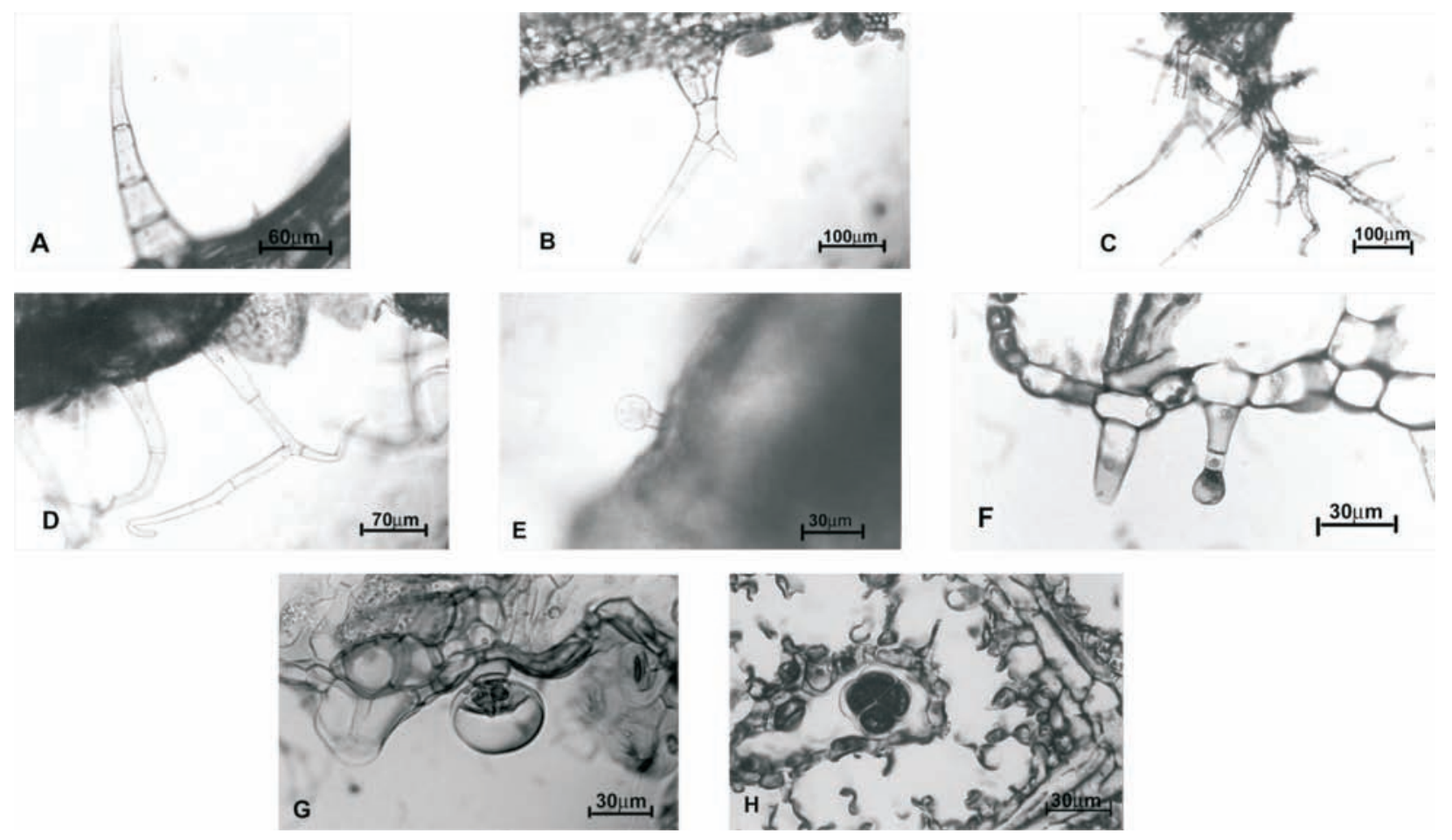

Figura 2. Tricomas tectores e glandulares presentes nas folhas de H. canum. A. tricoma tector pluricelular simples presente na epiderme adaxial; B. tricoma tector pluricelular ramificado presente na epiderme adaxial; C e D. tricomas tectores ramificados presentes na epiderme abaxial; E e F. tricomas glandulares com pedúnculos curtos presentes em ambas as epidermes; G. tricoma glandular peltado com cabeça tetracelular presente na epiderme abaxial; H. tricoma glandular peltado com cabeça tetracelular presente na epiderme abaxial em vista frontal. A, B, D, E e G. secções transversais em coloração azul de alcian/safranina; C. secção transversal submetida ao reagente de Steinmetz; F e H. Secção em coloração Safrablau. 

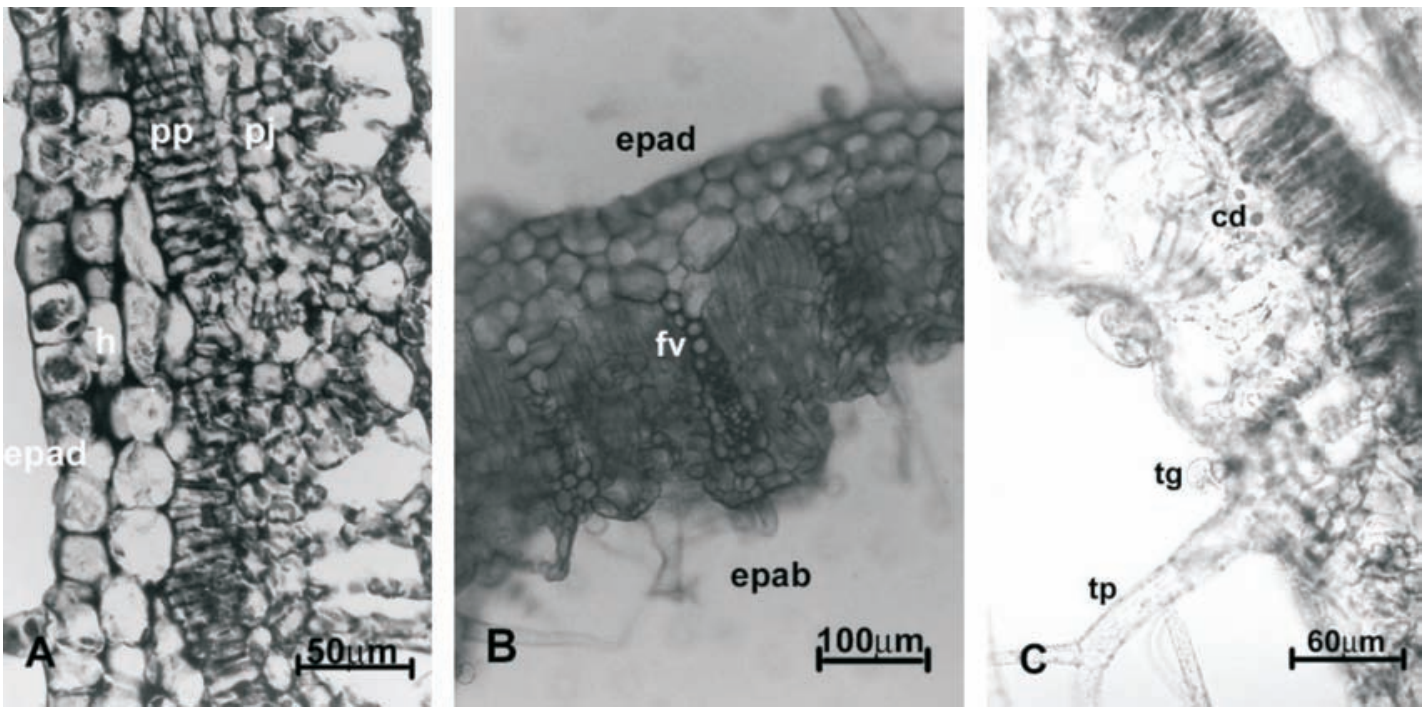

Figura 3. Secções transversais da lâmina foliar de Hyptidendron canum. A. aspecto geral do mesofilo em coloração Safrablau; B. aspecto geral do mesofilo em coloração com azul de alcian/safranina; C. detalhe do mesofilo. cd: cristal tipo drusa; epad: epiderme adaxial; epab: epiderme abaxial; fv: feixe vascular com extensão de bainha; h: hipoderme; pp: parênquima paliçádico; pj: parênquima lacunoso (esponjoso); tg tricoma glandular; tp: tricoma tector pluricelular ramificado da epiderme abaxial.
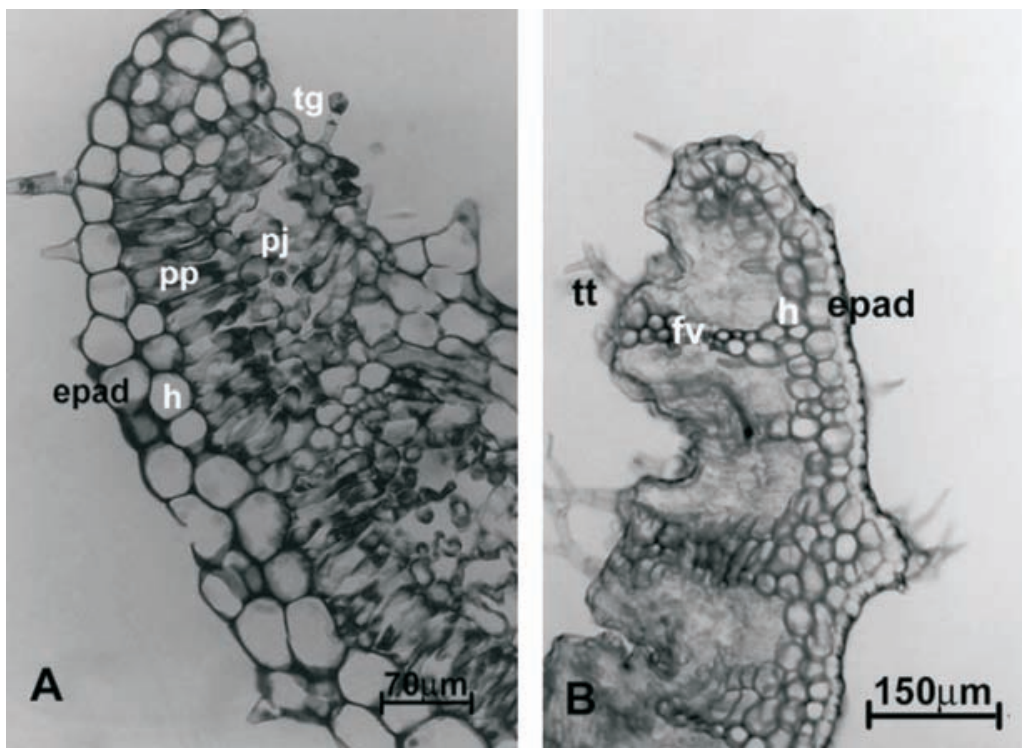

Figura 4. Secções transversais do bordo mediano das folhas de Hyptidendron canum. A. aspecto geral em coloração safrablau: B. aspecto geral em coloração azul de alcian/safranina. epad: epiderme adaxial; h: hipoderme; fv: feixe vascular; pp: parênquima paliçádico; pj: parênquima lacunoso (esponjoso); tg: tricoma glandular; tt: tricoma tector.

O caule na região do primeiro e segundo entrenó, em secção transversal, apresenta forma quadrangular (Figura 7A), característica freqüente na família Lamiaceae, com epiderme unisseriada contendo tricomas tectores pluricelulares simples e ramificados (Figura 7B), tricomas glandulares capitados com pedúnculo curto unicelular e cabeça unicelular e bicelular (Figura 7C) e tricomas glandulares peltados com cabeça tetracelular (Figura 7D). Nas secções realizadas no primeiro entrenó observase colênquima angular com várias camadas de células e parênquima cortical com até quatro camadas de células. O sistema vascular é constituído por feixes colaterais. $\mathrm{O}$ parênquima medular apresenta células de tamanhos variados no primeiro e segundo entrenó (Figuras 7A e 7B). No cilindro vascular observa-se início de crescimento secundário (Figura 7B). No segundo entrenó, o parênquima cortical apresenta algumas células com paredes lignificadas e externamente ao floema presença de fibras pericíclicas (Figura 7E). Observa-se instalação do felogênio no colênquima (Figura 7E) e, no cilindro vascular, presença do câmbio vascular em atividade, observando floema e 

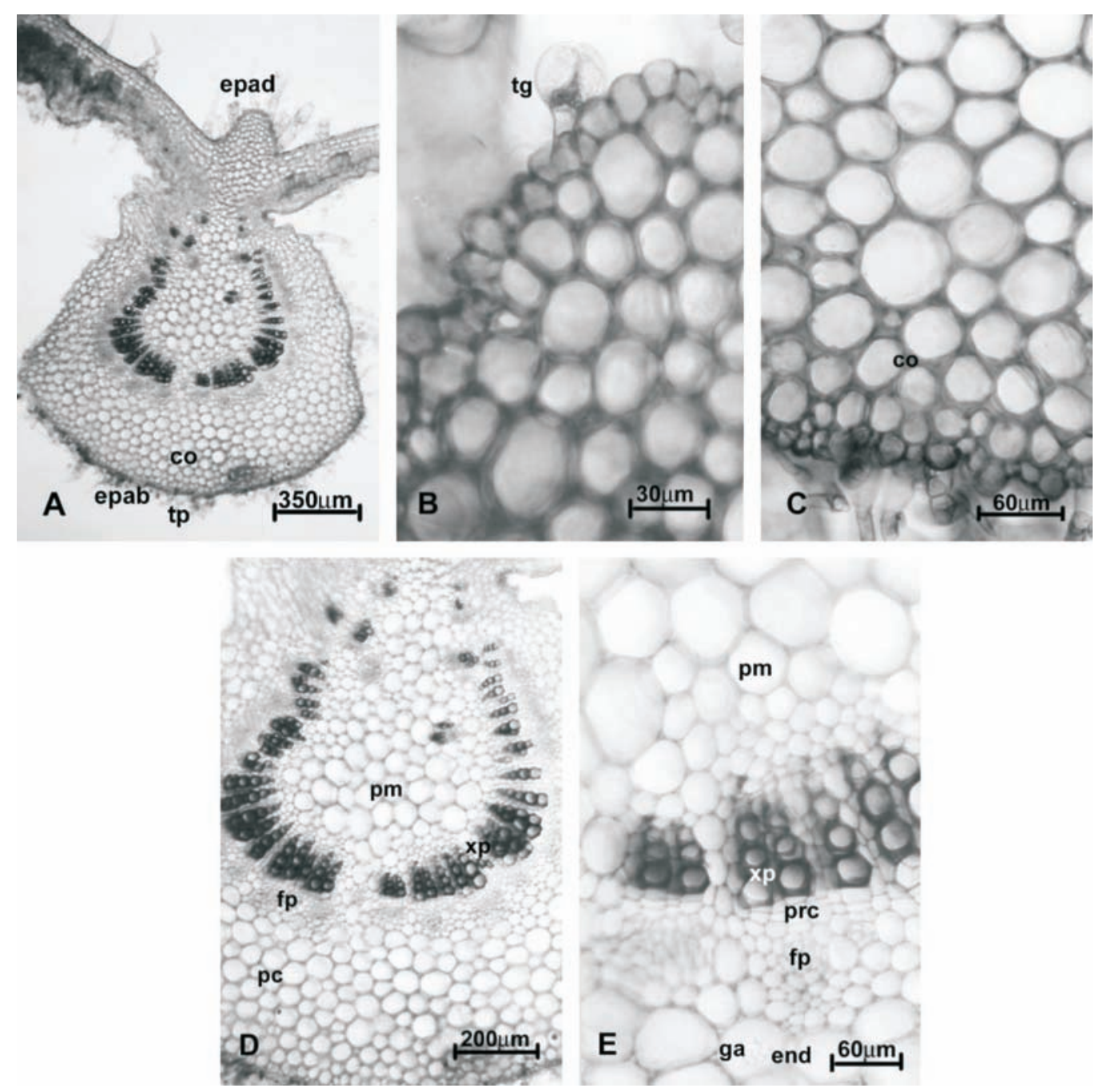

Figura 5. Secções transversais da nervura principal da folha de H. canum. A. aspecto geral; B. detalhe da epiderme adaxial com tricoma glandular; C. detalhe da epiderme abaxial e colênquima; D. sistema vascular central; E. detalhe dos feixes vasculares; coloração azul de alcian/safranina. prc: procâmbio; co: colênquima; end: endoderme; epad: epiderme adaxial; epab: epiderme abaxial; fp: floema primário; ga: grãos de amido; pc: parênquima cortical; pm: parênquima medular; tp: tricoma tector ramificado; tg: tricoma glandular; xp: xilema primário.

xilema secundários (Figura 7E).

Na microscopia do pó das folhas de H. canum submetido ao reagente de Steinmetz observam-se fragmentos de epiderme abaxial contendo estômatos, tricomas tectores pluricelulares ramificados e fragmentos de elementos de vasos com espessamento espiralado.

\section{Testes de pureza}

O teor de cinzas totais das folhas de $H$. canum foi de $6,34 \%$, cinzas insolúveis de $0,001 \%$ e o teor de umidade $9,3 \%$.

\section{Reações de identificação de metabólitos secundários}

As reações realizadas com o pó das folhas de $H$. canum evidenciaram a presença de glicosídeos flavônicos e saponínicos. Não foram detectados nesta amostra alcalóides, amido, cumarinas, antraquinonas, esteróides e triterpenos, cardiotônicos e taninos.

Obtenção do extrato etanólico, frações e perfil em CCD

O rendimento do extrato etanólico bruto foi de $8,66 \%$ e das frações de $29,61 \%$ para a fração hexano, $23,79 \%$ para a fração clorofórmica e $4,13 \%$ para a fração acetato de etila.

A fase móvel que melhor separou os componentes foi acetona/tolueno/ácido fórmico (3:3:1). A análise em CCD indicou a presença de terpenos na fração hexânica; terpenos e flavonóides na fração clorofórmica; flavonóides e lignanas na fração acetato de etila; e flavonóides, saponinas e lignanas na fração metanol/água.

\section{Doseamento de flavonóides}

O teor de flavonóides totais encontrados na amostra de $H$. canum foi de $0,95 \%$. 

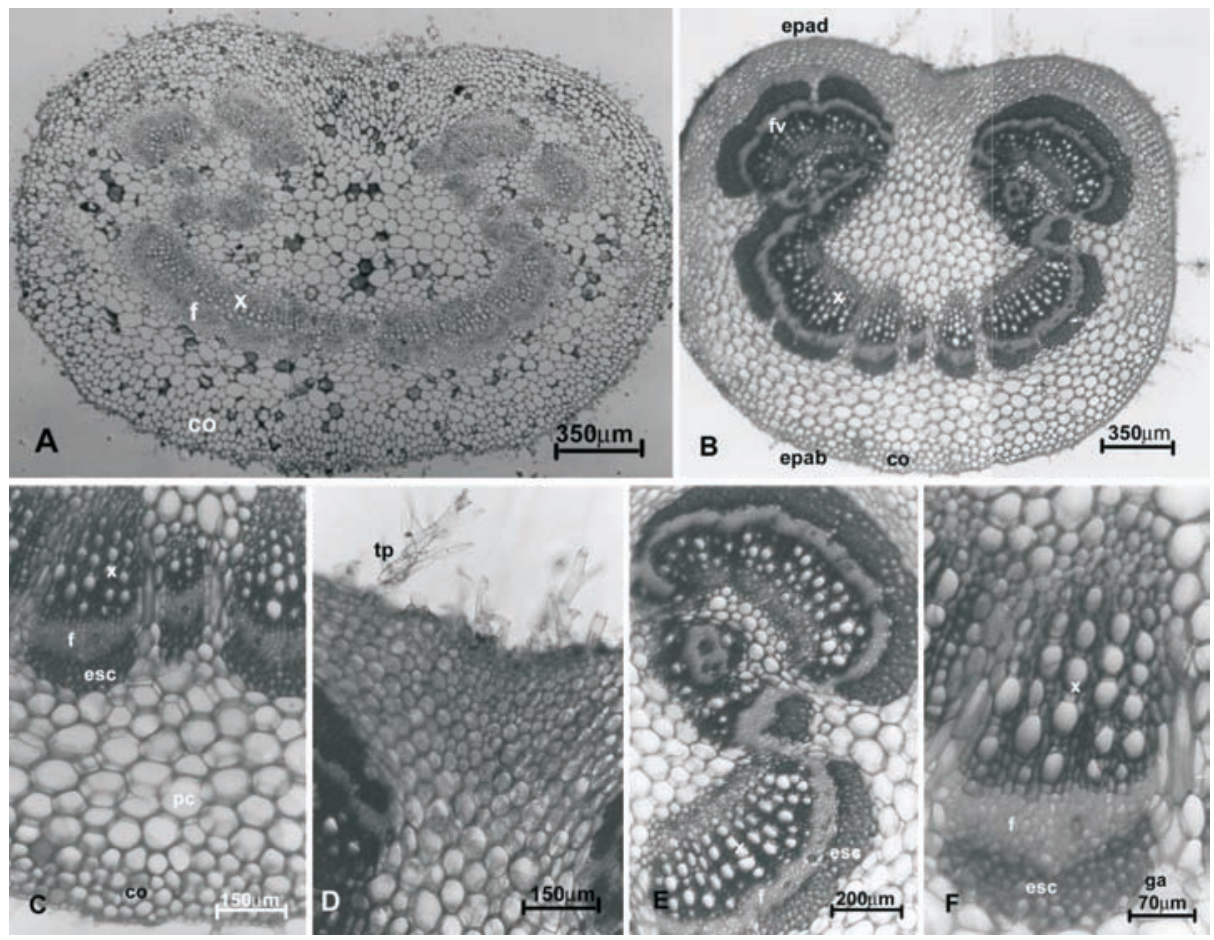

Figura 6. Secções transversais do pecíolo da folha de H. canum. A. aspecto geral do pecíolo em coloração Safrablau; B. aspecto geral; C. detalhe da epiderme abaxial, colênquima, parênquima cortical e feixes vasculares; D. detalhe da epiderme adaxial com tricomas tectores ramificados; E. detalhe de feixes vasculares laterais próximos à epiderme superior; F. detalhe de feixes vasculares próximo à epiderme abaxial; C, D, E e F. coloração com azul de alcian/safranina. co: colênquima; epab: epiderme abaxial; epad: epiderme adaxial; esc: esclerênquima; f: floema; fv: feixes vasculares colaterais; ga: grãos de amido; pc: parênquima cortical; tp: tricoma tector ramificado; x: xilema.
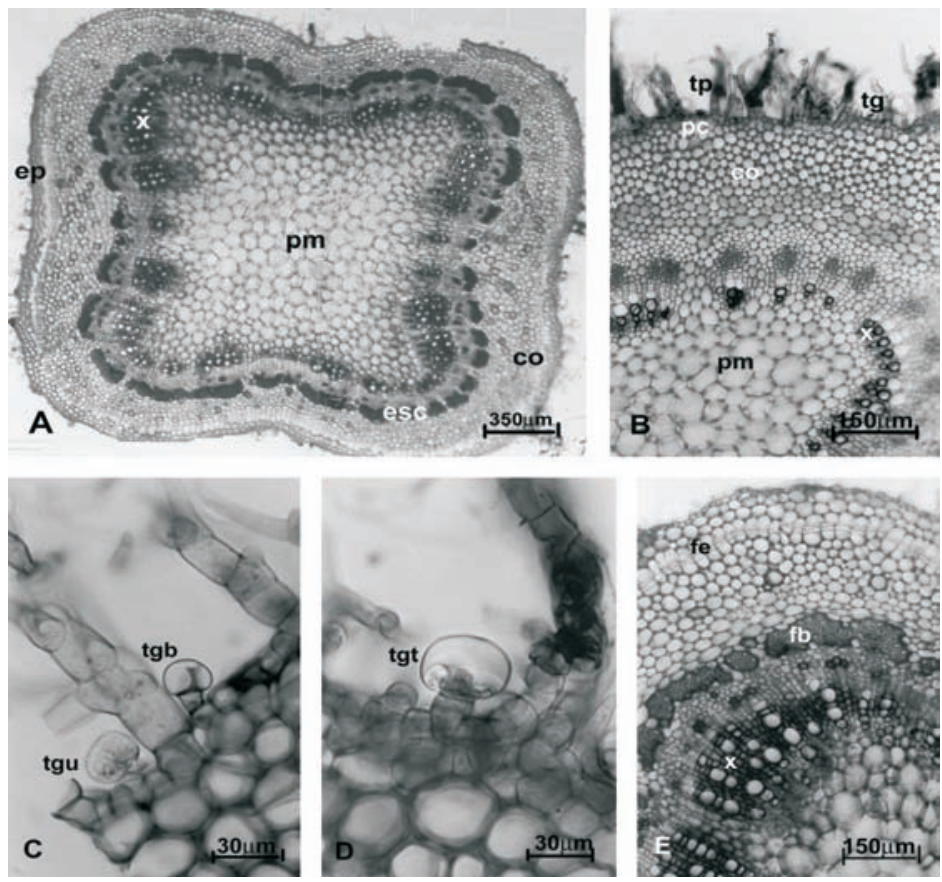

Figura 7. Secções transversais do caule jovem de Hyptidendron canum. A. aspecto geral do caule do segundo entrenó; B. detalhe do caule, primeiro entrenó; C. tricomas glandulares capitados com pedúnculo curto com cabeça unicelular e bicelular; D. tricoma glandular peltado com cabeça tetracelular; E. detalhe do caule, segundo entrenó. A, B, C, D e E. Coloração com azul de Alcian/ safranina. prc: procâmbio; co: colênquima; ep: epiderme; esc: esclerênquima; fe: felogênio; f: floema; fb: fibras pericíclicas; pc: parênquima cortical; pm: parênquima medular; tg: tricoma glandular; tgu: tricomas glandulares capitados com pedúnculo curto unicelular e cabeça unicelular; tgb: tricomas glandulares capitados com pedúnculo curto unicelular e cabeça bicelular; tgt: tricoma glandular peltado com cabeça tetracelular; tp: tricoma tector pluricelular; x: xilema. 


\section{DISCUSSÃO}

Através da análise morfo-anatômica realizada neste estudo, observou-se a presença de estômatos anisocíticos e diacíticos na epiderme abaxial das folhas de $H$. canum. Os estômatos diacíticos são mais comuns na família Lamiaceae (Metcalfe \& Chalk, 1950), mas estômatos anisocíticos já foram registrados nas folhas de outras espécies como em Hyptis ovalifolia Benth. e Hyptis rugosa Benth. (Rezende et al., 2003).

Tricomas glandulares peltados e capitados observados na epiderme em ambas as faces das folhas do $H$. canum foram identificados também nas folhas de Ocimum selloi Benth. (Lamiaceae) (Costa et al., 2007) e de Cunila microcephala Benth. (Toledo et al., 2004), sendo estruturas características de espécies da família Lamiaceae.

Aspectos anatômicos das folhas de H. canum, como presença de mesofilo dorsiventral, parênquima paliçádico unisseriado e presença de inclusões citoplasmáticas em forma de drusas foram descritos nas folhas de outras espécies da família Lamiaceae como Mentha spicata L., o híbrido Mentha spicata X suaveolens (Martins, 2002) e Cunila microcephala Benth. (poejinho) (Toledo et al., 2004).

Assim como encontrado nas folhas de H. canum, Rezende et al. (2003) identificaram sistema vascular colateral, em arco contínuo ou interrompido centralmente por fileiras de células parenquimáticas nas folhas de Hyptis lanata Pohl ex Benth. (Lamiaceae), Hyptis nudicaulis Benth., Hyptis ovalifolia Benth. e Hyptis rugosa Pohl ex Benth.; e Toledo et al. (2004) nas folhas de Cunila microcephala Benth. (Lamiaceae).

O caule jovem de $H$. canum apresentou forma quadrangular com tricomas tectores simples e ramificados e glandulares. Estas características estão presentes em outras espécies da família Lamiaceae (Metcalfe \& Chalk, 1950), como por exemplo, em Leonurus sibiricus L. (Duarte \& Lopes, 2005), Hedeoma multiflora Benth., Hyptis lappacea Benth., Salvia pallida Benth. e Salvia procurrens Benth. (Novoa et al., 2005). Os tricomas são anexos epidérmicos, sendo que os tectores possuem função protetora, evitando a transpiração excessiva, e os glandulares caracterizam-se pela presença de glândulas secretoras de óleos essenciais (Oliveira \& Akisue, 1995).

As reações com o pó das folhas de $H$. canum evidenciaram a presença de glicosídeos flavônicos e saponínicos. $\mathrm{Na}$ análise em $\mathrm{CCD}$ verificou-se a presença de flavonóides nas frações acetato de etila e clorofórmio; terpenos nas frações hexano e clorofórmio; lignanas na fração acetato de etila; e flavonóides, saponinas e lignanas na fração metanol/água. Flavonóides, terpenos e saponinas são constituintes químicos encontrados em outras espécies da família Lamiaceae como Orthosiphon stamineus Benth. (Accame, 2000); Mentha spicata L. (Sánchez et al., 1998); Coleus amboinicus Lour. (Hernández et al., 2002); Ocimum basilicum L. (Rodrigues \& Gonzaga. 2001); Satureja boliviana (Benth.) Briq. (Lizarraga \& Abdala, 2004) e Ocimum gratissimum L. (Junaid et al., 2006). De acordo com Harley e Reynolds (1992), a presença de terpenóides é característica nas espécies da família Lamiaceae, os quais possuem atividade inseticida, antibacteriana e antifúngica, tendo um possível papel de defesa nestas plantas. Zuanazzi e Montanha (2004) descrevem que alguns medicamentos são elaborados a partir de flavonóides, em particular para o tratamento de doenças circulatórias, hipertensão e agindo como cofator da vitamina C. Outros flavonóides são responsáveis por uma ação antitumoral considerável, podendo agir como antivirais, anti-hemorrágicos, hormonais, antiinflamatórios, antimicrobianos e antioxidante Por sua vez, drogas vegetais contendo saponinas são utilizadas tradicionalmente como expectorantes e diuréticas (Schenkel et al., 2004). Estudos químicos e biológicos devem ser desenvolvidos para verificar a relação entre os metabólitos secundários presentes e o uso tradicional de $H$. canum.

Por meio deste estudo observou-se que as folhas e caules do H. canum apresentaram características anatômicas e metabólitos secundários semelhantes aos encontrados em outras espécies da família Lamiaceae. Este trabalho contribuiu significativamente para o conhecimento da morfoanatomia e para identificação dos grupos químicos presentes em $H$. canum.

\section{REFERÊNCIAS}

Accame MEC 2000. Compuestos fenólicos. Panorama Actual Med 24: 340-344.

Brandão M 1991. Plantas Medicinais do Cerrado Mineiro. Inf Agrapec 15: 15-20.

Bukastsch 1972 apud Kraus JE, Arduin M 1997. Manual básico de métodos em morfologia vegetal. Rio de Janeiro, Brasil: EDUR. Editora Universidade Rural.

Costa AF 2001. Farmacognosia. Lisboa: Calouste Gulbenkian.

Costa LC, Castro EM, Pinto JEBP, Alves E, Bertolucci SKV, Rosal L F, Moreira CM 2007. Aspectos da anatomia foliar de Ocimum selloi Benth. (Lamiaceae) em diferentes condições de qualidade de luz. Rev Bras Biocien 5: 6-8.

Duarte MR, Lopes JF 2005. Morfoanatomia foliar e caulinar de Leonuros sibiricus L., Lamiaceae. Acta Farm Bonaerense 24: 68-74.

Eitten G 1994. Vegetação do Cerrado. In: Pinto M.N. (org) Cerrado; caracterização, ocupação e perspectivas. Brasília: UnB, p.45-60.

Epling C 1949. Revisión del Género Hyptis (Labiatae). Revista Del Museo de La Plata. Tomo VII, Sección Botânica: 153-497.

Farmacopéia Brasileira 1988. $4^{\mathrm{a}}$ ed. Parte I São Paulo: Editora Atheneu.

Farmacopéia Brasileira 2001. $4^{\mathrm{a}}$ ed. Parte II. Fasc. 3. São Paulo: Editora Atheneu.

Farmacopéia Brasileira 2003. $4^{\text {a }}$ ed. Parte II. Fasc. 5. São Paulo: Editora Atheneu.

Ferri, PH 1996. Química de Produtos Naturais: Métodos Gerais. 
In: Di Stasi, L C (org) Plantas Medicinais Arte e Ciências. Um Guia de Estudo Interdisciplinar. São Paulo: Editora Universidade Estadual Paulista, p. 129-156.

Ferri PH, Ferreira HD 1992. Fitoquímica das folhas de Hyptis Benth. Semana de Química. Goiânia, Brasil.

Harley RM 1988. Revision of generic limits in Hyptis Jacq. (Labiatae) and its allies. Bot J Linn Soc 98: 87-95.

Harley RM, Reynolds T 1992. Labiate Science. Richmond, Surrey, UK:Royal Botanic Gardens Kew.

Hernández JLU, Valero H, Gilotaiza R 2002. 23 especies vegetales medicinales de uso frecuente em la población de Tabay. Rev Facultad de Farm 44: 51-58.

Johansen DA 1940. Plant microtechnique. New York: McGrawHill Book.

Junaid AS, Olabore AO, Onwuliri FC, Okwori AEJ, Agina SE 2006. The antimicrobial properties of Ocimum gratissimum extracts on some selected bacterial gastrointestinal isolates. Afr J Biotechnol 5: 2315-2321.

Kraus JE, Arduin M 1997. Manual básico de métodos em morfologia vegetal. Rio de Janeiro: EDUR. Editora Universidade Rural.

Leite JPV, Pimenta DS, Gomes RSDL, Dantas-Barros AM 2007. Contribuição ao estudo farmacobotânico da Echinodorus macrophyllus (Kunth) Micheli (chapéu-de-couro) Alismataceae. Rev Bras Farmacogn 17: 242-248.

Lizarraga E, Abdala LR 2004. Compuestos fenólicos mayoritarios em Satureja boliviana (Benth.) Briq (Lamiaceae). Acta Farm Bonaerense 23: 198-200.

Martins MBG 2002. Botânica e Fisiologia Vegetal. Estudos de microscopia óptica e de microscopia eletrônica de varredura em folhas de Mentha spicata e de Mentha spicata X suaveolens (Lamiaceae). Bragantia 61: $205-$ 218.

Mentz LA, Bordignon SAL 2004. Nomenclatura Botânica, Classificação e Identificação de Plantas Medicinais. In: Simões CMO, Schenkel EP, Gosmann G, Melo JCP, Mentz LA, Petrovick PR (orgs). Farmacognosia da planta ao medicamento. Porto Alegre/Florianópolis: UFRGS/UFSC, p. 211-227.

Metcalfe CR, Chalk L 1950. Anatomy of the Dicotyledons. Systematic Anatomy of the Leaf and Stem. USA: Oxford University Press.

Novoa MC, Monti C, Vizcaíno CE 2005. Anatomia y etnobotánica de cuatro espécies de Labiatae de la Província Biogeográfica Pampeana, usadas em la medicina popular. Acta Farm Bonaerense 24: 512-520.

Oliveira F, Akisue G 1995. Fundamentos de Farmacobotânica. São Paulo, Rio de Janeiro, Belo Horizonte: Editora Atheneu.

Rezende MH, Dias HF, Pereira DN, Zugaro P, Coutinho CA, Leite RH de SB, Nascimento VP, Faria MT, Schliewe MA 2003. Anatomia foliar de quatro espécies de Hyptis (Labiatae) ocorrentes em Goiás. 54 ${ }^{\circ}$ Congresso Nacional de Botânica. Belém, Brasil.

Rodrigues VG, Gonzaga DSOM 2001. Manjericão. Ocimum basilicum L. Folder 10 - Série "Plantas Medicinais". Rondônia: Embrapa.

Sánchez LE, Leal LIM, Pino IJ, Carbalho TC 1998. Estandarización de Mentha spicata L. medicamento herbario con actividad antiespasmódica. Rev Cubana Plant Med 3: 26-30.

Sass JE 1951. Botanical microtechnique. Iowa: State Press.

Schenkel EP, Gosmann G, Athayde ML 2004. Saponinas. In:
Simões CMO, Schenkel EP, Gosmann G, Melo JCP, Mentz LA, Petrovick PR (orgs). Farmacognosia da planta ao medicamento. Porto Alegre/Florianópolis: UFRGS/UFSC, p. 711-740.

Souza VC, Lorenzi H 2005. Botânica Sistemática. Guia ilustrado para identificação das famílias de Angiospermas da flora brasileira, baseado em APG II. Nova Odessa, SP: Instituto Plantarum.

Toledo MGT, Alquini Y, Nakashima T 2004. Caracterização anatômica das folhas de Cunila microcephala Benth. (Lamiaceae). Braz J Pharm Sci 40: 487-493.

Vuaden ER, Maria Albuquerque MCF, Coelho MFB, Mendonça EAF 2005. Germinação e morfologia de sementes e de plântulas de hortelã-do-campo Hyptis cana Pohl. (Lamiaceae). Rev Bras Sementes 27: 1-5.

Wagner H, Bladt S 2001. Plant Drug Analysis. A Thin Layer Chromatography Atlas. $2^{\text {nd }}$ Ed. Berlim: Springer.

Zuanazzi JAS, Montanha JA 2004. Flavonóides. In: Simões CMO, Schenkel EP, Gosmann G, Melo JCP, Mentz LA, Petrovick PR (orgs). Farmacognosia da planta ao medicamento. Porto Alegre/Florianópolis: UFRGS/ UFSC, p. 577-614. 